\title{
Prussian Blue Modified Solid Carbon Nanorod Whisker Paste Composite Electrodes: Evaluation towards the Electroanalytical Sensing of $\mathrm{H}_{2} \mathrm{O}_{2}$
}

\author{
Carolin Siimenson, ${ }^{1}$ Jaanus Kruusma, ${ }^{1}$ Erik Anderson, ${ }^{1}$ Maido Merisalu, ${ }^{2}$ \\ Väino Sammelselg, ${ }^{1,2}$ Enn Lust, ${ }^{1}$ and Craig E. Banks ${ }^{3}$ \\ ${ }^{1}$ Institute of Chemistry, University of Tartu, Ravila Street 14A, Tartu 50411, Estonia \\ ${ }^{2}$ Institute of Physics, University of Tartu, Riia Road 142, Tartu 51014, Estonia \\ ${ }^{3}$ Division of Chemistry and Environmental Science, School of Science and the Environment, Faculty of Science and Engineering, \\ Manchester Metropolitan University, Chester Street, Manchester M1 5GD, Lancs, UK
}

Correspondence should be addressed to Craig E. Banks, c.banks@mmu.ac.uk

Received 18 October 2011; Accepted 20 December 2011

Academic Editor: Boniface Kokoh

Copyright (c) 2012 Carolin Siimenson et al. This is an open access article distributed under the Creative Commons Attribution License, which permits unrestricted use, distribution, and reproduction in any medium, provided the original work is properly cited.

Metallic impurity free solid carbon nanorod "Whiskers" (SCNR Whiskers), a derivative of carbon nanotubes, are explored in the fabrication of a Prussian Blue composite electrode and critically evaluated towards the mediated electroanalytical sensing of $\mathrm{H}_{2} \mathrm{O}_{2}$. The sensitivity and detection limits for $\mathrm{H}_{2} \mathrm{O}_{2}$ on the paste electrodes containing 20\% (w/w) Prussian Blue, mineral oil, and carbon nanorod whiskers were explored and found to be $120 \mathrm{~mA} /\left(\mathrm{M} \mathrm{cm}^{2}\right)$ and $4.1 \mu \mathrm{M}$, respectively, over the concentration range 0.01 to $0.10 \mathrm{mM}$. Charge transfer constant for the 20\% Prussian Blue containing SCNR Whiskers paste electrode was calculated, for the reduction of Prussian Blue to Prussian White, to reveal a value of $1.8 \pm 0.21 / \mathrm{s}(\alpha=0.43, N=3)$. Surprisingly, our studies indicate that these metallic impurity-free SCNR Whiskers, in this configuration, behave electrochemically similar to that of an electrode constructed from graphite.

\section{Introduction}

The investigation of new carbon nanomaterials continues to be a hot topic. Such materials have received attention due to their reported optimal sensing properties $[1,2]$, for example, Gooding et al. have elegantly demonstrated that carbon nanotubes may "wire" biomolecules facilitating charge transfer between the electrode and the redox-active centre of the protein [3]. Despite the reported excellent properties of carbon nanomaterials, the question about the origin of the enhanced charge transfer speed and the reduction of the overpotentials is still questionable. This is due to the different crystallographic and chemical influences affecting the electrochemical properties of carbon nanotubes [4]. As Compton et al. [5, 6], Banks et al. [4, 7, 8], and later Pumera et al. $[9,10]$ have demonstrated, metallic impurities reside in carbon nanotubes which is inherent to their fabrication process can be responsible for the CNTs observed electroactivity towards selected analytes; for example, Banks et al. [11] concluded for the case of the electrochemical detection of D-glucose that the effect of metallic impurities dominates over edge plane crystallographic effects of the graphite edge plane like-sited/defects.

In a previous report [12] the electrochemical reduction of $\mathrm{H}_{2} \mathrm{O}_{2}$ on carbon nanorod paste electrode (SCNRPE) prepared without the use of d-metallic catalysts has been reported. In that study, hydrogen peroxide was selected as one of model compounds since its detection is often needed, for example, in studying oxidative stress in bio-systems $[13,14]$, low temperature fuel cell processes, $[15,16]$ and in the studies of corrosion processes $[17,18]$. Paste electrodes, as selected in this study, as working electrodes are useful because they (1) are simple to prepare and handle, (2) demonstrate reasonable reproducibility, (3) have a low 
background current, (4) can be easily recleaned, (5) have a low cost, (6) can be used in a wide potential range [19, 20], and (7) minimise diffusion within the nano material network neglecting the influence of thin layer diffusion allowing more readily to determine the charge transfer rate constants via cyclic voltammetry [21]. Also they can be easily modified with analyte-specific enzymes or redox mediators $[19,20]$.

In this paper we investigate the electrochemical behaviour of Prussian Blue (PB) as a charge transfer mediator due to its reported use as a $\mathrm{H}_{2} \mathrm{O}_{2}$ overpotential reducer [22-24], with metallic impurity-free solid carbon nanorod "Whiskers" (SCNR Whiskers), a derivative of carbon nanotubes behaving as the charge transfer catalysts. The SCNR "whiskers" were chosen due to their relative novelty and lack of metallic catalytic additives commonly found in carbon nanotubes where $\mathrm{PB}$ is selective to the reduction of $\mathrm{O}_{2}$ and especially to $\mathrm{H}_{2} \mathrm{O}_{2}$, has high stability, and has no saturation effect for substrate [22]. PB has been previously used in a combination with carbon nanotubes, $[23,25]$ glassy carbon [26], and other materials [22] to prepare paste electrodes. To construct robust and fast prepared paste electrodes having direct electrical contact between the SCNR particles, we decided to blend the SCNR "whiskers" with PB. Note that the use of these nanomaterials allows one to deconvolute the true electrochemical parameters avoiding contributions from metallic impurities [4, 7-10]. The PB composite electrodes are evaluated towards the electroanalytical sensing of hydrogen peroxide and compared critically to that of simple graphite; surprisingly we find no advantage of using the SCNR "whiskers" in this context.

\section{Experimental}

The solid carbon nanorod (SCNR) "whiskers" are commercially available and were kindly provided by SCNTE and are in fact a subclass of multiwalled carbon nanotubes. Full characterisation has been reported previously of these materials in [27]. Such characterisation of the material with Raman spectroscopy reveals a large D-peak corresponding to high level of "defects" on the tubes. in this case a large number of "kinks" and other features have been supposed to lead to the high edge plane character of the "tubes." The relative density of the electroactive edge plane sites has been calculated from cyclic voltammetry measurements and was found to be $c a .13 .3 \%$ being much higher than for the other forms of carbon materials [21]. Mineral oil (suitable for the preparation of Nujol mulls for IR, stabilizer free) to prepare carbon nanotube paste electrodes was obtained from Sigma-Aldrich. All other chemicals used were of analytical grade and were used as received without any further purification, obtained also from Sigma-Aldrich. All aqueous solutions were prepared using Milli-Q (Millipore) water with resistivity not less than $18.2 \mathrm{M} \Omega \cdot \mathrm{cm}$.

To construct robust and fast prepared paste electrodes having direct electrical contact between SCNRs we decided to blend these with $\mathrm{PB}$ powder with mineral oil as a binder. The PB was decided not to be chemically attached to SCNR due to low electrical conductivity of dry PB, [28-30], experimentally shown in the work of Ricci et al. [26]. where they needed to include unmodified glassy carbon particles into the paste to have useful electrochemical response that is, electrical connection between particles therein. The Prussian Blue modified carbon nanotube paste electrodes were prepared by weighting SCNR, PB powder, and the mineral oil in the needed proportions. All substances were carefully mixed with each other and the prepared paste was pressed into a cylinder constructed by BASi (type MF2010 , inner diameter of the tube $3.0 \mathrm{~mm}$ ) previously cleaned with acetone and Milli-Q water. The surface of the electrode was re-cleaned by a soft clean filter paper and washed then with the Milli-Q water before each measurement cycle.

Electrochemical measurements were performed with an Autolab PGSTAT 30 potentiostat connected with a PC. A large area platinum mesh served as a counter electrode and an $\mathrm{Ag} / \mathrm{AgCl}(3 \mathrm{M} \mathrm{NaCl}$ aq., BASi) was used as the reference electrode completing the circuit. All solutions in the electrochemical cell $(5 \mathrm{~mL})$ were purged for 15 minutes with Ar gas (99.9999\%, AGA) prior to the start of the electrochemical experiments. All experiments were conducted at room temperature $\left(25 \pm 1^{\circ} \mathrm{C}\right)$.

Scanning electron microscopic (SEM) images were obtained using Helios Nanolab 600 FIB (FEI Company) instrument. Instrument settings: applied voltage: $10.00 \mathrm{kV}$, current: $43 \mathrm{pA}$, electron source to object distance (WD): $5.0 \mathrm{~mm}$, and detector: TLD. For the electron photographing $10 \mu \mathrm{L}$ of the ethanolic suspensions of carbon nanorods $(1 \mathrm{mg} / \mathrm{mL})$ were deposed onto precleaned $\mathrm{Au}(111)$ disks. This suspension was Sonicated $120 \mathrm{~s}$ in a sonobath (Elmasonic S 10 , type $510,60 \mathrm{~W}, v=37 \mathrm{kHz}$ ) prior to the deposition onto Au disks.

\section{Results and Discussion}

To understand the nature of the carbon nanorods (SCNR) used and to examine the material in light of its high proportionation of reported edge plane defects, predicted in [27], we performed SEM. As depicted in Figure 1 the SCNR are dispersed over a Au (111) surface lying horizontally tending to aggregate. Also, different sizes of the nanorods are obvious. Figure 2 presents a larger magnification of a group of nanorods and this image indicates that the surface structure of the nanorods is quite variable. Some of the rods seem to be quite smooth (large degree of graphite base planes visible), while some of them seem to have very rough surface (large degree of graphite edge planes and surface defects are visible). Figure 3 is an amplification of a SCNR having a high-surface roughness. It appears that the edge planes are oriented under $90^{\circ}$ to the axle appearing on the side of the rod, so that the ends of nanorods are formed from the basal plane of graphite. On the other hand, some rods in Figure 2 expose base planes on the side(s) and the ends of the SCNR consist in edge planes. From the SEM images we concluded that the SCNRs have "dual" orientation and a very high ratio of exposed edge planes and defects. This phenomenon should make this material 


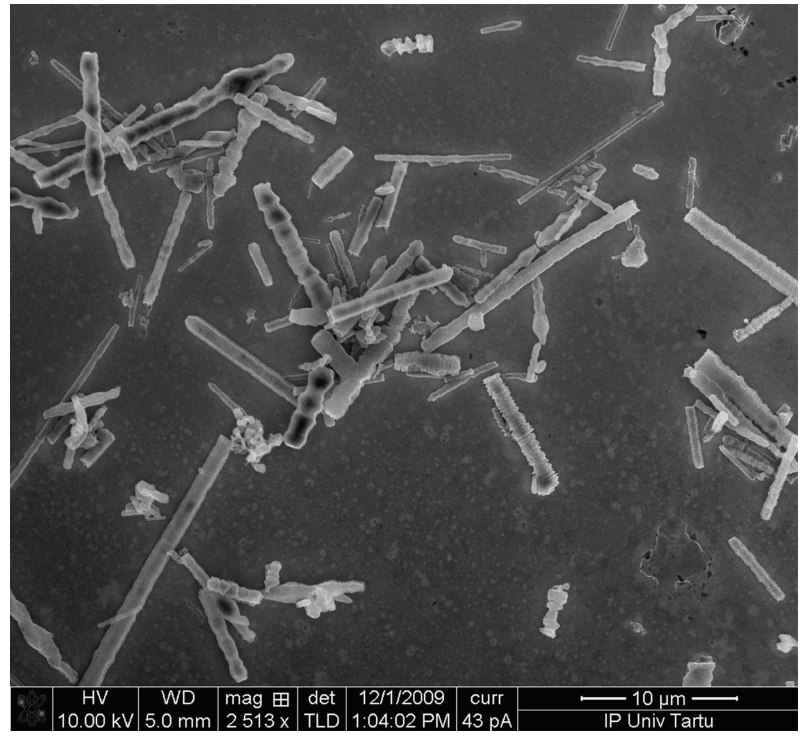

Figure 1: SEM image of the SCNRs, magnified 2513x.

quite electroactive, while the existence of exposed edge planes increases the charge transfer speed between the SCNR and a reacting substance $[4,31]$. The SCNR "whiskers" have the lengths in the order of 1-5 microns, with a diameter from $20 \mathrm{~nm}$ to $1 \mu \mathrm{m}$ which are made up of highly "kinked" bundles of nanorods and have no empty core just consisting in a single solid core with multiple walls making up the material. Raman spectroscopy of this material $[27,32]$ shows (using a $785 \mathrm{~nm}$ laser excitation wavelength) well-defined G peaks with a very large $G^{*}$ intensity and a smaller $D: G$ ratio as compared with the commercial CNT material. The $785 \mathrm{~nm}$ excitation frequency allows observation of two key features in SCNR morphology as compared with MWCNTs which is due to the consistency of the material. The RBM vibrations present at 115 and $170 \mathrm{~cm}^{-1}$ are also observed. The Raman data also show that SCNRs produced via CTCC are metallically conductive. Analysis of the purity (measured via ICP-MS) reveals a carbon mass $\%$ of 99.98 with a oxygen mass $\%$ of $<0.05$ and a silicon mass $\%$ of 0.01 indicating the absence of metallic impurities as it is often in the case of other commercially available carbon nanomaterials $[5,6]$.

\subsection{Cyclic Voltammetric Studies of PB Modified Carbon}

Nanorod Paste Electrodes. To investigate the influence of the $\mathrm{PB}$ on charge transfer processes, using hydrogen peroxide as a model compound, two different pastes were prepared containing 10 and 20\% (w/w) PB (see Table 1 for exact composition). total content of solid substances in the paste electrodes was always kept close to $70 \%(\mathrm{w} / \mathrm{w})$ as it was found to be optimal as reported in a previous study [12]. Figure 4 shows three cyclic voltammetric curves resulting from the electrochemical reduction of hydrogen peroxide $(10 \mathrm{mM})$ in $0.1 \mathrm{M}$ phosphate buffer solution $(\mathrm{pH}=7.0)$. Two of these curves are measured on the PB-modified SCNR paste electrode and one on the bare $0 \%(\mathrm{w} / \mathrm{w})$ PB modified SCNR paste electrode. Clear reduction peaks corresponding to the

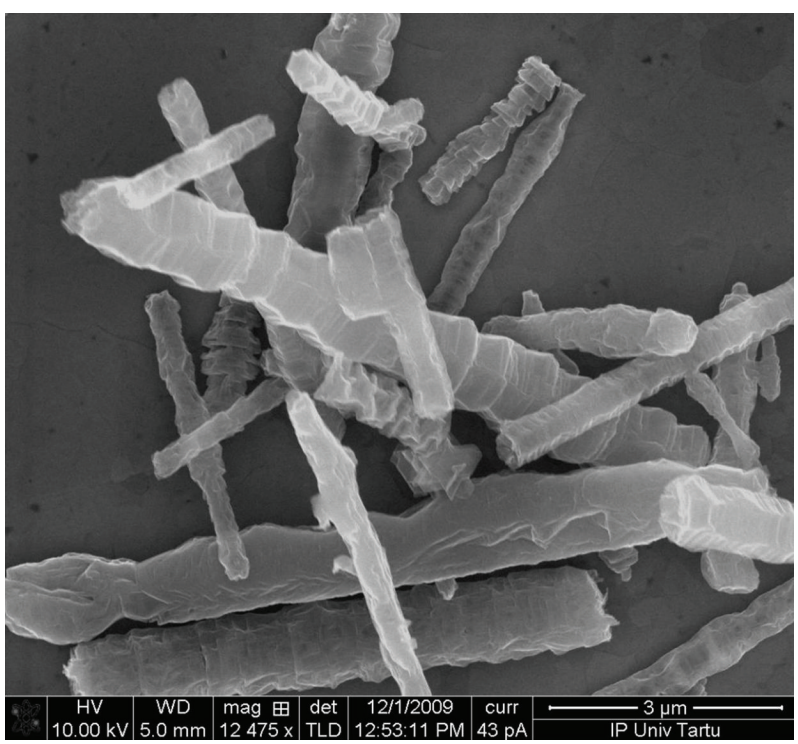

FIGURE 2: SEM image of the SCNRs, magnified 12475x.

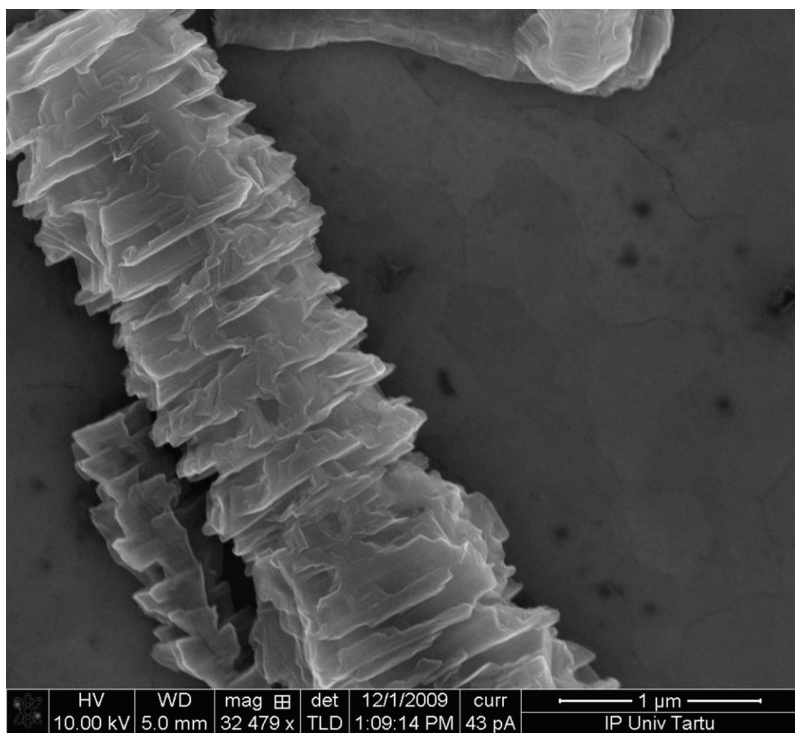

FIGURE 3: Closer SEM image of the SCNRs"', magnified 32479x.

electrochemical reduction of $\mathrm{H}_{2} \mathrm{O}_{2}$ are visible at the peak potential $-1.37 \mathrm{~V}$ versus $\mathrm{Ag} / \mathrm{AgCl}(3 \mathrm{M} \mathrm{NaCl})$ at a potential sweep rate of $25 \mathrm{mV} / \mathrm{s}$. When the electrode potential becomes more cathodic than $-1.6 \mathrm{~V}, \mathrm{H}_{3} \mathrm{O}^{+}$ions start to reduce. When $\mathrm{PB}$ is added to the paste, the overpotential of the hydrogen peroxide reduction process significantly lowers. On the $10 \%$ PB-modified paste electrode no clear reduction peak of $\mathrm{H}_{2} \mathrm{O}_{2}$ appears $(v=50 \mathrm{mV} / \mathrm{s})$. It seems that this reduction process starts from the potentials $-0.8 \mathrm{~V}$ (being lower than that for $0 \% \mathrm{~PB}$ modified paste electrode), the reduction current of $\mathrm{H}_{2} \mathrm{O}_{2}$ reaches the maximum at $E \approx-1.4 \mathrm{~V}$ and seems smoothly to continue to rise with the proton's reduction process at more negative potentials than $-1.46 \mathrm{~V}$ versus 


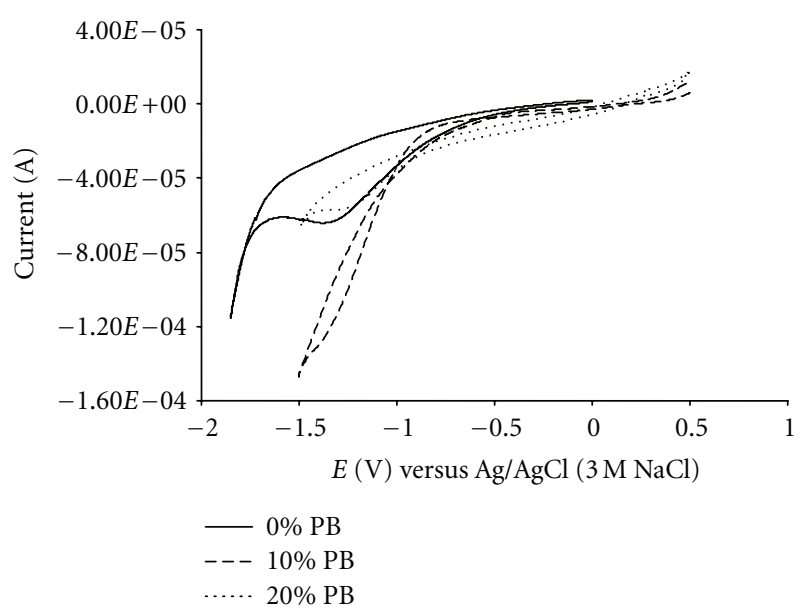

Figure 4: Reduction process of $\mathrm{H}_{2} \mathrm{O}_{2}$ on SCNR paste electrodes containing $0 \%(\mathrm{w} / \mathrm{w})$ PB (solid line), $10 \%(\mathrm{w} / \mathrm{w})$ PB (dashed line), and $20 \%\left(\mathrm{w} / \mathrm{w}\right.$ ) $\mathrm{PB}$ (dotted line). $10.0 \mathrm{mM} \mathrm{H}_{2} \mathrm{O}_{2}$ in $0.1 \mathrm{M}$ phosphate buffer, $\mathrm{pH}=7.0$. Scan rate $25 \mathrm{mV} / \mathrm{s}$ for SCNR paste electrode containing no $\mathrm{PB}$ and $\mathrm{v}=50 \mathrm{mV} / \mathrm{s}$ for SCNR paste containing 10 and $20 \%(\mathrm{w} / \mathrm{w}) \mathrm{PB}$.

TABLE 1

\begin{tabular}{lccc}
\hline Paste electrode & $\begin{array}{c}\text { Mineral oil, } \\
(\mathrm{w} / \mathrm{w}) \%\end{array}$ & SCNR, (w/w) \% & $\mathrm{PB},(\mathrm{w} / \mathrm{w}) \%$ \\
\hline "0\% PB" & 32.0 & 68.0 & 0.0 \\
"10\% PB" & 29.8 & 60.1 & 10.1 \\
"20\% PB" & 30.0 & 50.0 & 20.0 \\
\hline
\end{tabular}

$\mathrm{Ag} / \mathrm{AgCl}(3 \mathrm{M} \mathrm{NaCl})$. Therefore no exact quantitative analysis of $\mathrm{H}_{2} \mathrm{O}_{2}$ is possible to be performed on this electrode.

Next a SCNR paste electrode containing $20 \%(\mathrm{w} / \mathrm{w})$ PB-modified SCNR paste electrode was prepared. A small reduction peak of $\mathrm{H}_{2} \mathrm{O}_{2}$ forms at peak potential $-1.2 \mathrm{~V}$ versus $\mathrm{Ag} / \mathrm{AgCl}(3 \mathrm{M} \mathrm{NaCl}), v=50 \mathrm{mV} / \mathrm{s}$. At more cathodic potentials than $-1.4 \mathrm{~V}$ the $\mathrm{H}_{3} \mathrm{O}^{+}$starts to reduce. Comparing this with the unmodified SCNR paste electrode we can see that hydrogen evaluation starts at $c a .-1.6 \mathrm{~V}$ versus $\mathrm{Ag} / \mathrm{AgCl}(3 \mathrm{M} \mathrm{NaCl})$. It is clear that on the PB-modified SCNR electrodes the $\mathrm{H}_{3} \mathrm{O}^{+}$reduction starts at $c a .200 \mathrm{mV}$ lower overpotential compared to the unmodified electrode. From inspection of the cyclic voltammetric curves on the Figure 4 it is visible also that the overpotential of the reduction of $\mathrm{H}_{2} \mathrm{O}_{2}$ has reduced less than that of $\mathrm{H}_{3} \mathrm{O}^{+}$. The overpotential of the $\mathrm{H}_{3} \mathrm{O}^{+}$reduction process is the most decreased at $10 \%(\mathrm{w} / \mathrm{w})$ PB-modified SCNR paste electrode causing the $\mathrm{H}_{2} \mathrm{O}_{2}$ and $\mathrm{H}_{3} \mathrm{O}^{+}$reduction process to overlap. While the hydrogen formation was more intensive on the PB-modified electrodes than on the unmodified SCNR paste electrode, cyclic voltammetric sweeps were stropped at potential $-1.5 \mathrm{~V}$ to avoid electrode surface passivation due to the formation of hydrogen bubbles. Applying slower sweep rates than $50 \mathrm{mV} / \mathrm{s}$, the hydrogen deposes on the surface of the electrode and the hysteresis forms in the cyclic voltammogram (not shown on the figure). Comparing the CV-s obtained on $0 \% \mathrm{~PB}$ and $20 \% \mathrm{~PB}$ modified paste electrodes (Figure 4) we can conclude that the presence of $\mathrm{PB}$ does reduce the overpotential of $\mathrm{H}_{2} \mathrm{O}_{2}$ reduction by $60 \mathrm{mV}$, but on the other hand the charge transfer intensity has decreased as well.

Performing cyclic voltammetry $(v=50 \mathrm{mV})$ over the potential range from 0.5 to $-0.5 \mathrm{~V}$ versus $\mathrm{Ag} / \mathrm{AgCl}(3 \mathrm{M}$ $\mathrm{NaCl})$ a broad reduction peak with a current maxima at the potential $c a .0 .130 \mathrm{~V}$ versus $\mathrm{Ag} / \mathrm{AgCl}(3 \mathrm{M} \mathrm{NaCl})$ is a result of the reduction process of $\mathrm{PB}$ to Prussian White $(\mathrm{PW})$ and a wide oxidation peak with a peak potential at $0.275 \mathrm{~V}$ characteristic of the reoxidation process of $\mathrm{PW}$ to $\mathrm{PB}$ (Figure 5, dashed line). The formal potential was calculated as the mean value of the anodic and cathodic peak potentials and was found to be $0.202 \mathrm{~V}$ versus $\mathrm{Ag} / \mathrm{AgCl}(3 \mathrm{M} \mathrm{NaCl})$. solid line presents a cyclic voltammetric curve measured on the unmodified SCNR PE (68\% w/w SCNR and 32\% w/w oil) in the potential range from -1 to $1 \mathrm{~V}$ versus $\mathrm{Ag} / \mathrm{AgCl}(3 \mathrm{M}$ $\mathrm{Ag} / \mathrm{AgCl}$ ) measured in the same experimental conditions. As it is obvious from Figure 5, no characteristic redox-peaks of $\mathrm{PB}$ are visible on the unmodified SCNR paste electrode. The difference between reduction and oxidation peaks of the PB $\leftrightarrow$ PW electrochemical process is $147 \mathrm{mV}$, closer to Prussian Blue graphite paste electrode $\left(\Delta E_{p}=124 \mathrm{mV}\right)$ suggesting that the metallic impurity free SCNR Whiskers behave graphitelike.

A charge transfer rate constant for the reduction of Prussian Blue to Prussian White in 20\% Prussian Blue containing SCNR Whiskers paste electrode was calculated applying Laviron equation [33]:

$$
\begin{aligned}
\log k_{s}= & \alpha \log (1-\alpha)+(1-\alpha) \log \alpha-\log \left(\frac{R T}{n F v}\right) \\
& -\frac{\alpha(1-\alpha) \mathrm{nF} \Delta E_{p}}{2.3 \mathrm{RT}},
\end{aligned}
$$

where $\alpha$ is charge transfer coefficient, $\Delta E_{p}$ is anodic and cathodic peak potential difference $[V], F$ is Faraday number $[\mathrm{C} / \mathrm{mol}], k_{s}$ is heterogeneous charge transfer rate constant, $n$ is number of electrons transferred in the reaction, $R$ is gas universal coefficient $[\mathrm{J} /(\mathrm{K} \mathrm{mol})], v$ is $\mathrm{CV}$ potential sweep rate $[\mathrm{V} / \mathrm{s}]$, and $T$ is solution temperature $[\mathrm{K}] . \alpha$ was found from the slope of the $E_{p}$ versus $\ln v$ relationship (where $\Delta E_{p}>200 \mathrm{mV}$, at $n=1$ ) of the same cathodic process:

$$
\begin{aligned}
& \mathrm{KFe}^{\mathrm{III}} \mathrm{Fe}^{\mathrm{II}}(\mathrm{CN})_{6}+\mathrm{K}^{+}+\mathrm{e}^{-} \longrightarrow \mathrm{K}_{2} \mathrm{Fe}^{\mathrm{II}} \mathrm{Fe}^{\mathrm{II}}(\mathrm{CN})_{6} \text {. } \\
& \text { (Prussian Blue) (Prussian White) }
\end{aligned}
$$

A charge transfer rate constant value of $1.8 \pm 0.21 / \mathrm{s}(\alpha=$ $0.43, N=3$ ) was consequently deduced.

3.2. Determination of the limit of Detection (LOD) and Sensitivity of 20\% (w/w) PB-Modified SCNRPE. To investigate the electroanalytical properties of prepared $\mathrm{PB}$-modified SCNR paste electrodes, the $20 \%(\mathrm{w} / \mathrm{w})$ PB was selected due to lower $\mathrm{H}_{2} \mathrm{O}_{2}$ reduction overpotential and more obvious current maximum in the cyclic voltammogram of the $\mathrm{H}_{2} \mathrm{O}_{2}$ reduction process. First we investigated the rise of the reduction current of PB upon the concentration of added hydrogen peroxide. Despite the literature reports that the reduction current of $\mathrm{PB}$ should be dependent upon $\mathrm{H}_{2} \mathrm{O}_{2}$ 


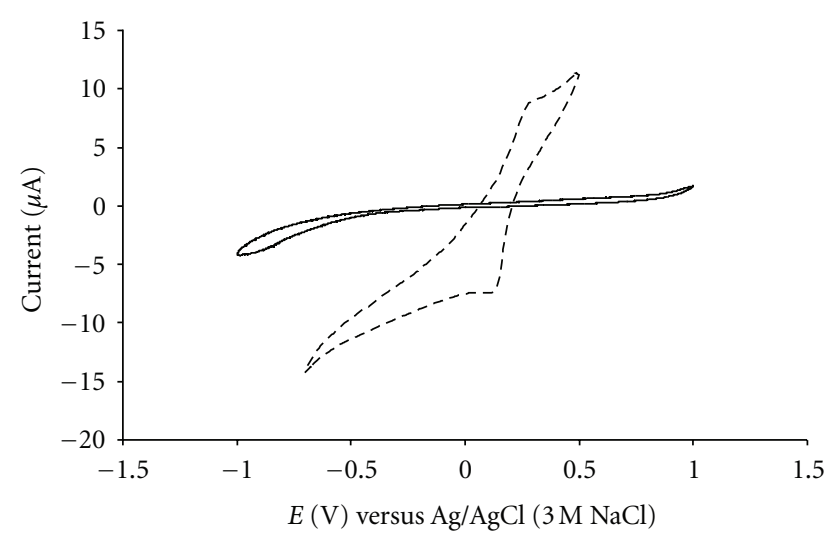

FIGURE 5: Cyclic voltammetric curves measured on the unmodified SCNR paste electrode $(68 \% \mathrm{w} / \mathrm{w}$ SCNR and $32 \% \mathrm{w} / \mathrm{w}$ oil, solid line) and $20 \%(\mathrm{w} / \mathrm{w})$ PB SCNR paste electrode (dashed line). $v=$ $50 \mathrm{mV} / \mathrm{s}, 0.1 \mathrm{M}$ phosphate buffer $(\mathrm{pH}=6.9)$.

concentration in the solution, we observed no acceptable correlation there. Therefore we moved to investigate the electrochemical reduction process of $\mathrm{H}_{2} \mathrm{O}_{2}$ itself. As marked above, the hydrogen peroxide gave a small wave at potential $-1.0 \mathrm{~V}$ versus $\mathrm{Ag} / \mathrm{AgCl}(3 \mathrm{M} \mathrm{NaCl}), v=50 \mathrm{mV} / \mathrm{s}$. We repeated this experiment in the concentration range from 1.0 to $10.0 \mathrm{mM}$. Figure 6 shows the cyclic voltammograms of the reduction of $\mathrm{H}_{2} \mathrm{O}_{2}$ at different concentrations. The sensitivity of the PB-modified electrode in the concentration range studied was $37 \mathrm{~mA} /\left(\mathrm{M} \mathrm{cm}^{2}\right)$ at $v=50 \mathrm{mV} / \mathrm{s}$. This is in the same range as found by us for unmodified SCNRPE $\left(50 \mathrm{~mA} /\left(\mathrm{M} \mathrm{cm}^{2}\right)\right)$ [12] or by Ricci and Palleschi $\left(45 \mathrm{~mA} /\left(\mathrm{M} \mathrm{cm}^{2}\right)\right)$ for $\mathrm{PB}$-modified carbon paste electrode [22]. calculated detection limit was $3.1 \mathrm{mM}$ being better than found for unmodified SCNRPE [12] and the relative standard deviation of the $\mathrm{H}_{2} \mathrm{O}_{2}$ reduction peak current stability measured at $\mathrm{H}_{2} \mathrm{O}_{2}$ concentration $10.0 \mathrm{mM}$ was $4.9 \%$ $(N=72, v=100 \mathrm{mV} / \mathrm{s})$.

For the analysis of $\mathrm{H}_{2} \mathrm{O}_{2}$ in the concentration range 0.01 to $0.10 \mathrm{mM}$, when background current correction was performed, a detection limit of $4.1 \mu \mathrm{M}$ was obtained. The sensitivity of the used PB-modified electrode was in this concentration range $120 \mathrm{~mA} /\left(\mathrm{M} \mathrm{cm}^{2}\right)$ being close to the graphite screen printed electrodes $\left(137 \mathrm{~mA} /\left(\mathrm{M} \mathrm{cm}^{2}\right)\right.$ [34] and $\left.135 \mathrm{~mA} /\left(\mathrm{M} \mathrm{cm}^{2}\right)[35]\right)$.

3.3. Cyclic Voltammetric Studies of 10 and 20\% PB-Modified SCNR PE at Different Potential Sweep Rates. While no acceptable correlation between the reduction current of the $\mathrm{PB}$ and concentration of $\mathrm{H}_{2} \mathrm{O}_{2}$ being observed, the electrochemical behaviour of PB was next investigated. For this purpose the cyclic voltammetric measurements at different sweep rates were performed. Figure 7 shows obtained cyclic voltammograms for the modified SCNR PE containing $20 \% \mathrm{~PB}$. The peak current versus $v^{1 / 2}$ curve is linear with correlation coefficient $R^{2}=0.98$ (Figure 8). This linear relationship indicates that the reduction process of $\mathrm{H}_{2} \mathrm{O}_{2}$ appears to be in these conditions totally irreversible [36]

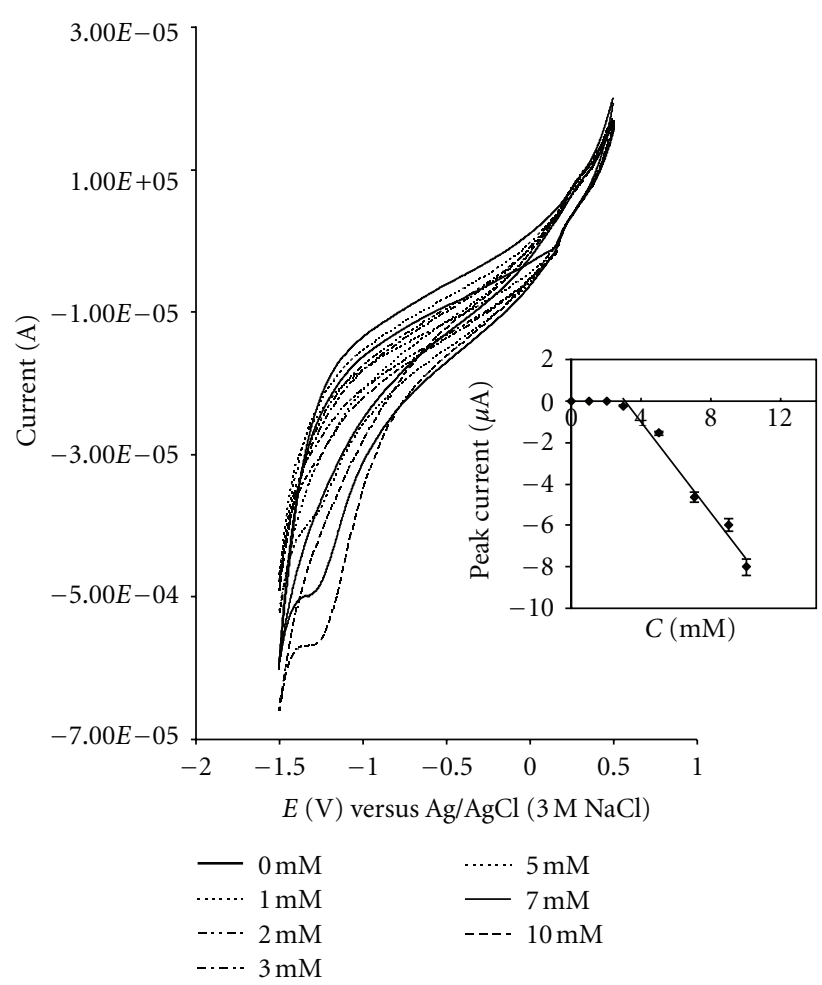

Figure 6: Reduction of $\mathrm{H}_{2} \mathrm{O}_{2}$ on $20 \%$ (w/w) modified PB SCNRPE. $v=50 \mathrm{mV} / \mathrm{s}, 0.1 \mathrm{M}$ phosphate buffer $(\mathrm{pH}=6.9)$.

while the reoxidation of the water to $\mathrm{H}_{2} \mathrm{O}_{2}$ was not observed (as it is obvious from the cyclic voltammograms also).

3.4. Investigation of the Redox Processes of $\mathrm{K}_{4}\left[\mathrm{Fe}(\mathrm{CN})_{6}\right]$ : Determination of the Charge Transfer Coefficient $\alpha$ and the Charge Transfer Rate Constant $k_{s}$. To investigate charge transfer speed on the 20\% PB modified SCNR PE, $10 \mathrm{mM}$ solution of $\mathrm{K}_{4}\left[\mathrm{Fe}(\mathrm{CN})_{6}\right]$ in $0.1 \mathrm{M}$ phosphate buffer $(\mathrm{pH}$ $=7$ ) was used as a probe. Cyclic voltammetric potential sweeps were performed in the potential range from -0.9 to $+1.0 \mathrm{~V}$ versus $\mathrm{Ag} / \mathrm{AgCl}$ and reverse. Data of the second cycle, measured in the potential sweep rate range from 0.5 to $6 \mathrm{~V} / \mathrm{s}$ (where the relationship between $E_{p}$ versus $\ln v$ was linear), were used for the calculation of $\alpha$ and $k$ values of the reduction process of $\mathrm{K}_{4}\left[\mathrm{Fe}(\mathrm{CN})_{6}\right]$ applying the Laviron equation [33]. The $\alpha$, found from slope of the $E_{p}$ versus $\ln$ $v$ (where $\Delta E_{p}>200 \mathrm{mV}$, at $n=1$ ) of the cathodic process (reduction of in situ presynthesized $\mathrm{K}_{3}\left[\mathrm{Fe}(\mathrm{CN})_{6}\right]$ ), has a value 0.6 and the average value for $k_{s}$ was $0.013 \pm 0.005 \mathrm{~s}^{-1}$. Value of $\alpha$ is the same as found by Huang in [37], but the charge transfer rate constant of the $\mathrm{K}_{3}\left[\mathrm{Fe}(\mathrm{CN})_{6}\right]$ reduction reaction, found by them on CNT-modified Au electrode, was higher: $k_{s}=0.31 \mathrm{~s}^{-1}$ [37]. The lower reduction process rate constant observed in this investigation suggests that in this context, the structure of SCNRs are not significantly advantageous over other CNTs. 


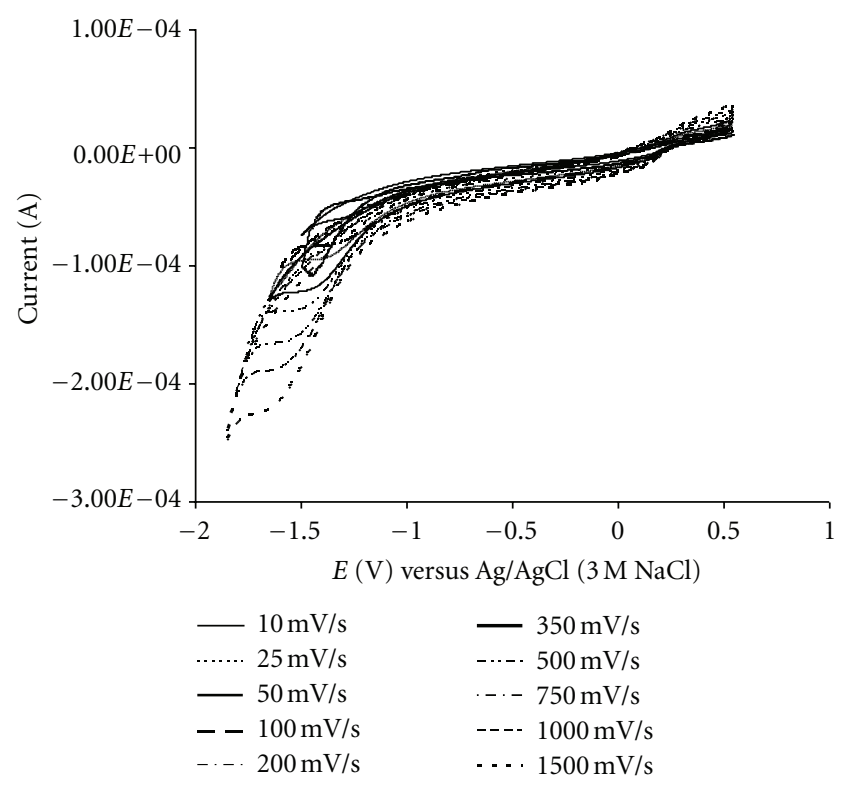

Figure 7: Cyclic voltammograms of $10 \mathrm{mM} \mathrm{H}_{2} \mathrm{O}_{2}$ at different sweep rates on $20 \%(\mathrm{w} / \mathrm{w})$ modified PB SCNRPE. $0.1 \mathrm{M}$ phosphate buffer, $\mathrm{pH}=7.0$.

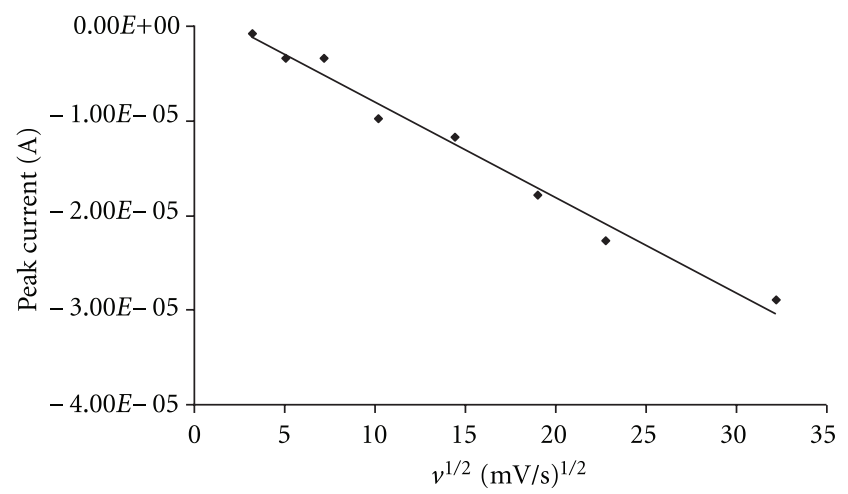

FIGURE 8: Dependence of the reduction peak current of $10 \mathrm{mM}$ $\mathrm{H}_{2} \mathrm{O}_{2}$ upon the square root of the potential sweep rate. $0.1 \mathrm{M}$ phosphate buffer, $\mathrm{pH}=7.0$.

\section{Conclusions}

In this work SCNR whisker paste electrodes have been investigated. SEM images of these virtually metallic impurity free carbon nanorods were obtained showing the existence of edge plains of the graphite on the side of these rods and basal planes at the ends of these rods. Some of the rods seem to be quite smooth (large degree of graphite basal planes were visible), while most of them seem to have very rough side surface (large amount of graphite edge planes and surface defects were visible). It appears that the edge planes were oriented under $90^{\circ}$ to the axle exposing themselves on the side of the rod, so that the ends of this nanorod were formed from the basal plane of graphite. From the SEM images, we may conclude that the SCNRs have "dual" orientation and a very high ratio of exposed edge planes of the graphite. These images confirm the results of earlier Raman spectroscopy studies of these SCNR materials [12]. Observed properties should make this material more electroactive while the existence of exposed edge planes and large number of crystal lattice defects increases the charge transfer speed between the SCNR and a reacting substance.

Three different SCNR paste electrodes were prepared containing 0,10 , and $20 \%(\mathrm{w} / \mathrm{w})$ PB. total content of solid substances in the paste electrodes was always kept close to $70 \%(\mathrm{w} / \mathrm{w})$ as it was found to be optimal in a previous study [12]. The reduction and speedup of the $\mathrm{H}_{3} \mathrm{O}^{+}$reduction process was the most intensive at $10 \%$ (w/w) PB-modified SCNR paste electrode when $\mathrm{H}_{2} \mathrm{O}_{2}$ and $\mathrm{H}_{3} \mathrm{O}^{+}$reduction processes overlap. When the SCNR paste electrode containing 20\% (w/w) PB-modified SCNR paste electrode was studied, a small reduction peak of $\mathrm{H}_{2} \mathrm{O}_{2}$ forms with a peak potential $-1.2 \mathrm{~V}$ versus $\mathrm{Ag} / \mathrm{AgCl}(3 \mathrm{M} \mathrm{NaCl})$ $(v=50 \mathrm{mV} / \mathrm{s})$. Due to the presence of PB on the SCNR the overpotential of $\mathrm{H}_{2} \mathrm{O}_{2}$ reduction decreased by $60 \mathrm{mV}$ compared to unmodified SCNR paste electrode. At a more cathodic potentials than $-1.4 \mathrm{~V}$ the $\mathrm{H}_{3} \mathrm{O}^{+}$cations started to reduce. Sensitivity of the $20 \% \mathrm{~PB}$-containing SCNR paste electrode to the hydrogen peroxide in the concentration range from 0.0010 to $0.010 \mathrm{M}$ was $37 \mathrm{~mA} /\left(\mathrm{M} \mathrm{cm}^{2}\right)(v=$ $50 \mathrm{mV} / \mathrm{s}$ ). This is in the same range as found by us for unmodified SCNR paste electrode $\left(50 \mathrm{~mA} /\left(\mathrm{M} \mathrm{cm}^{2}\right)\right)$ [12] or by Ricci and Palleschi $\left(45 \mathrm{~mA} /\left(\mathrm{M} \mathrm{cm}^{2}\right)\right)$ for PB-modified carbon paste electrode [22]. Along with this data and that of electrode kinetics, such results indicate no real advantage of the SCNR over that of graphite.

\section{Acknowledgments}

The authors thank Estonian Science Foundation (Grant no. GLOKT 8172) and Estonian Target Financial Project SF0180002s08 for their support.

\section{References}

[1] J. J. Gooding, "Nanostructuring electrodes with carbon nanotubes: a review on electrochemistry and applications for sensing," Electrochimica Acta, vol. 50, no. 15, pp. 3049-3060, 2005.

[2] G. A. Rivas, M. D. Rubianes, M. C. Rodríguez et al., "Carbon nanotubes for electrochemical biosensing," Talanta, vol. 74, no. 3, pp. 291-307, 2007.

[3] J. Liu, A. Chou, W. Rahmat, M. N. Paddon-Row, and J. J. Gooding, "Achieving direct electrical connection to glucose oxidase using aligned single walled carbon nanotube arrays," Electroanalysis, vol. 17, no. 1, pp. 38-46, 2005.

[4] X. Ji, R.O. Kadara, J. Kruusma, Q. Chen, and C.E. Banks, "Understanding the physico-electrochemical properties of carbon nanotubes: current state of the art," Electroanalysis, vol. 22, no. 1, pp. 7-19, 2010.

[5] B. Sljukic, C. E. Banks, and R. G. Compton, "Iron oxide particles are the active sites for hydrogen peroxide sensing at multiwalled carbon nanotube modified electrodes," Nano Letters, vol. 6, no. 7, pp. 1556-1558, 2006.

[6] C. E. Banks, A. Crossley, C. Salter, S. J. Wilkins, and R. G. Compton, "Carbon nanotubes contain metal impurities 
which are responsible for the "electrocatalysis" seen at some nanotube-modified electrodes," Angewandte Chemie, vol. 45, no. 16, pp. 2533-2537, 2006.

[7] J. Kruusma, N. Mould, K. Jurkschat, A. Crossley, and C. E. Banks, "Single walled carbon nanotubes contain residual iron oxide impurities which can dominate their electrochemical activity," Electrochemistry Communications, vol. 9, no. 9, pp. 2330-2333, 2007.

[8] J. Kruusma, V. Sammelselg, and C. E. Banks, "A systematic study of the electrochemical determination of hydrogen peroxide at single-walled carbon nanotube ensemble networks," Electrochemistry Communications, vol. 10, no. 12, pp. 18721875, 2008.

[9] M. Pumera, H. Iwai, and Y. Miyahara, "Bimetallic nickeliron impurities within single-walled carbon nanotubes exhibit redox activity towards the oxidation of amino acids," ChemPhysChem, vol. 10, no. 11, pp. 1770-1773, 2009.

[10] A. Ambrosi and M. Pumera, "Regulatory peptides are susceptible to oxidation by metallic impurities within carbon nanotubes," Chemistry, vol. 16, no. 6, pp. 1786-1792, 2010.

[11] L. Siegert, D. K. Kampouris, J. Kruusma, V. Sammelselg, and C. E. Banks, "The heterogeneity of multiwalled and singlewalled carbon nanotubes: iron oxide impurities can catalyze the electrochemical oxidation of glucose," Electroanalysis, vol. 21, no. 1, pp. 48-51, 2009.

[12] M. Merisalu, J. Kruusma, and C. E. Banks, "Metallic impurity free carbon nanotube paste electrodes," Electrochemistry Communications, vol. 12, no. 1, pp. 144-147, 2010.

[13] A. L. Brioukhanov and A. I. Netrusov, "Aerotolerance of strictly anaerobic microorganisms and factors of defense against oxidative stress: a review," Applied Biochemistry and Microbiology, vol. 43, no. 6, pp. 567-582, 2007.

[14] D. L. Coppock and C. Thorpe, "Multidomain flavin-dependent sulfhydryl oxidases," Antioxidants and Redox Signaling, vol. 8, no. 3-4, pp. 300-311, 2006.

[15] F. Alcaide, P. L. Cabot, and E. Brillas, "Fuel cells for chemicals and energy cogeneration," Journal of Power Sources, vol. 153, no. 1, pp. 47-60, 2006.

[16] B. Sljukic, C. E. Banks, and R. G. Compton, "An overview of the electrochemical reduction of oxygen at carbon-based modified electrodes," Journal of the Iranian Chemical Society, vol. 2, no. 1, pp. 1-25, 2005.

[17] A. Bergel, "Recent advances in electron transfer between biofilms and metals," in Proceedings of the 17th International Biohydrometallurgy Symposium (IBS '07), vol. 20-21 of Advanced Materials Research, pp. 329-334, 2007.

[18] J. Landoulsi, K. El Kirat, C. Richard, D. Féron, and S. Pulvin, "Enzymatic approach in microbial-influenced corrosion: a review based on stainless steels in natural waters," Environmental Science and Technology, vol. 42, no. 7, pp. 2233-2242, 2008.

[19] J. Barek, J. Fischer, T. Navrátil, K. Pecková, B. Yosypchuk, and J. Zima, "Nontraditional electrode materials in environmental analysis of biologically active organic compounds," Electroanalysis, vol. 19, no. 19-20, pp. 2003-2014, 2007.

[20] I. Švancara, K. Vytřas, K. Kalcher, A. Walcarius, and J. Wang, "Carbon paste electrodes in facts, numbers, and notes: a review on the occasion of the 50-years jubilee of carbon paste in electrochemistry and electroanalysis," Electroanalysis, vol. 21, no. 1, pp. 7-28, 2009.

[21] P. M. Hallam and C. E. Banks, "A facile approach for quantifying the density of defects (edge plane sites) of carbon nanomaterials and related structures," Physical Chemistry Chemical Physics, vol. 13, no. 3, pp. 1210-1213, 2011.
[22] F. Ricci and G. Palleschi, "Sensor and biosensor preparation, optimisation and applications of Prussian Blue modified electrodes," Biosensors and Bioelectronics, vol. 21, no. 3, pp. 389-407, 2005.

[23] F. Ricci, A. Amine, D. Moscone, and G. Palleschi, "Prussian Blue modified carbon nanotube paste electrodes: a comparative study and a biochemical application," Analytical Letters, vol. 36, no. 9, pp. 1921-1938, 2003.

[24] A. A. Karyakin, "Prussian blue and its analogues: electrochemistry and analytical applications," Electroanalysis, vol. 13, no. 10, pp. 813-819, 2001.

[25] M. Li, G. Zhao, Z. Yue, and S. Huang, "Sensor for traces of hydrogen peroxide using an electrode modified by multiwalled carbon nanotubes, a gold-chitosan colloid, and Prussian blue," Microchimica Acta, vol. 167, no. 3-4, pp. 167-172, 2009.

[26] F. Ricci, C. Gonçalves, A. Amine, L. Gorton, G. Palleschi, and D. Moscone, "Electroanalytical study of Prussian Blue modified glassy carbon paste electrodes," Electroanalysis, vol. 15, no. 14, pp. 1204-1211, 2003.

[27] P. M. Hallam, B. L. Riehl, B. D. Riehl, and C. E. Banks, "Solid carbon nanorod whiskers: application to the electrochemical sensing of biologically relevant molecules," RSC Advances, no. 1, pp. 93-99, 2011.

[28] M. K. Carpenter and R. S. Conell, "Electrolyte-free electrochromic device," Applied Physics Letters, vol. 55, no. 21, pp. 2245-2247, 1989.

[29] M. K. Carpenter and R. S. Conell, "Single-film electrochromic device," Journal of the Electrochemical Society, vol. 137, no. 8, pp. 2464-2467, 1990.

[30] A. Xidis and V. D. Neff, "On the electronic conduction in dry thin films of Prussian blue, Prussian yellow, and Everitt's salt," Journal of the Electrochemical Society, vol. 138, no. 12, pp. 3637-3642, 1991.

[31] M. Pumera, "The electrochemistry of carbon nanotubes: fundamentals and applications," Chemistry, vol. 15, no. 20, pp. 4970-4978, 2009.

[32] http://www.scnte.com/technology.html.

[33] E. Laviron, "General expression of the linear potential sweep voltammogram in the case of diffusionless electrochemical systems," Journal of Electroanalytical Chemistry, vol. 101, no. 1, pp. 19-28, 1979.

[34] M. P. O’Halloran, M. Pravda, and G. G. Guilbault, "Prussian Blue bulk modified screen-printed electrodes for $\mathrm{H}_{2} \mathrm{O}_{2}$ detection and for biosensors," Talanta, vol. 55, no. 3, pp. 605-611, 2001.

[35] F. Ricci, A. Amine, C. S. Tuta et al., "Prussian Blue and enzyme bulk-modified screen-printed electrodes for hydrogen peroxide and glucose determination with improved storage and operational stability," Analytica Chimica Acta, vol. 485, no. 1, pp. 111-120, 2003.

[36] A. J. Bard, G. Inzelt, and F. Scholz, Electrochemical Dictionary, Springer, Berlin, Germany, 2008.

[37] X. J. Huang, H. S. Im, O. Yarimaga et al., "Electrochemical behavior of needle-like and forest-like single-walled carbon nanotube electrodes," Journal of Electroanalytical Chemistry, vol. 594, no. 1, pp. 27-34, 2006. 


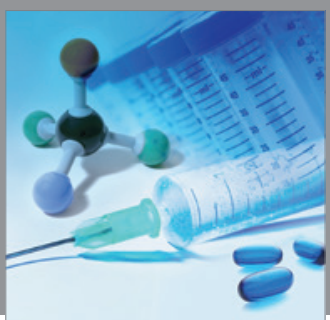

International Journal of

Medicinal Chemistry

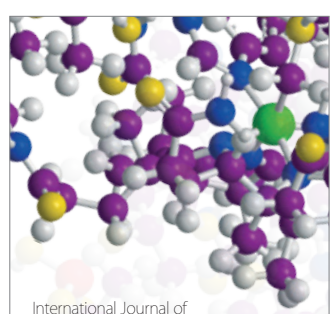

Carbohydrate Chemistry

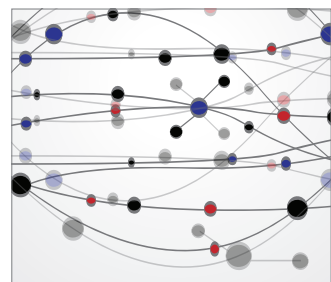

The Scientific World Journal
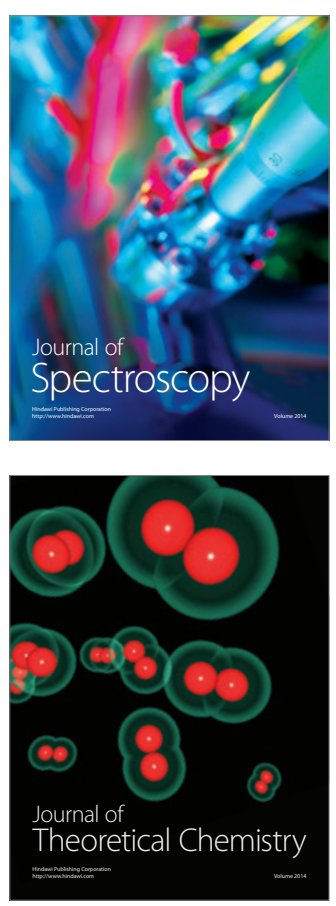
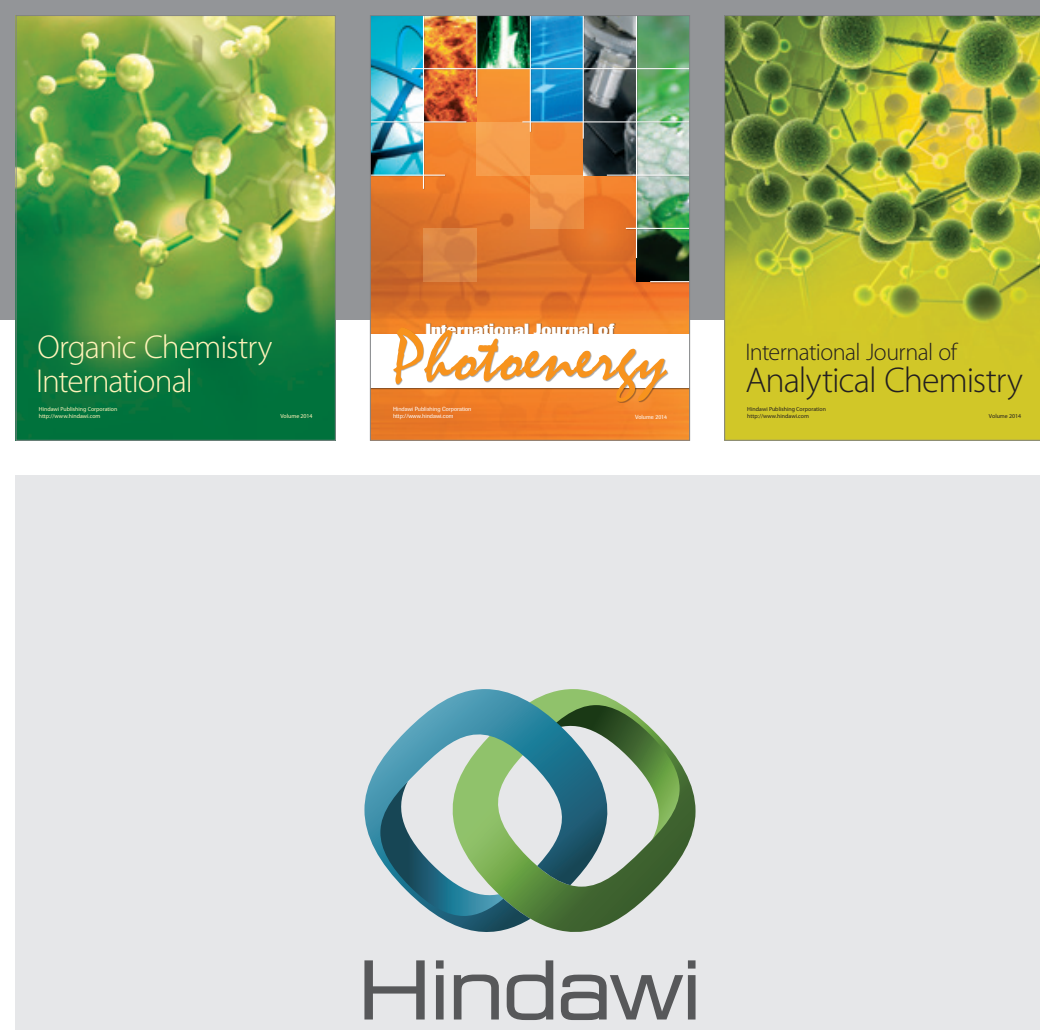

Submit your manuscripts at

http://www.hindawi.com
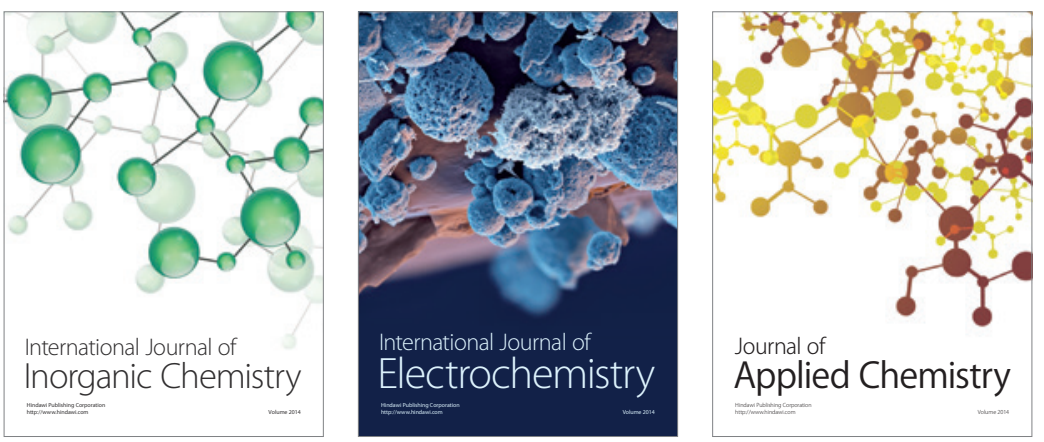

Journal of

Applied Chemistry
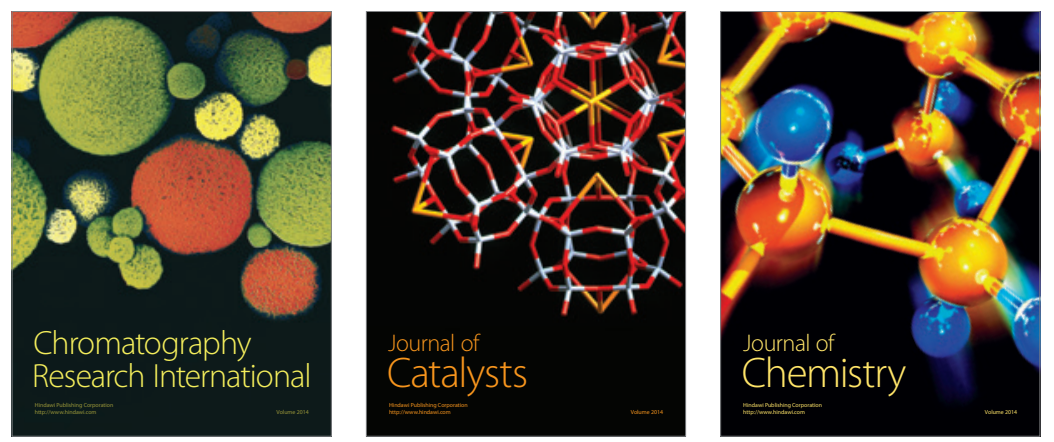
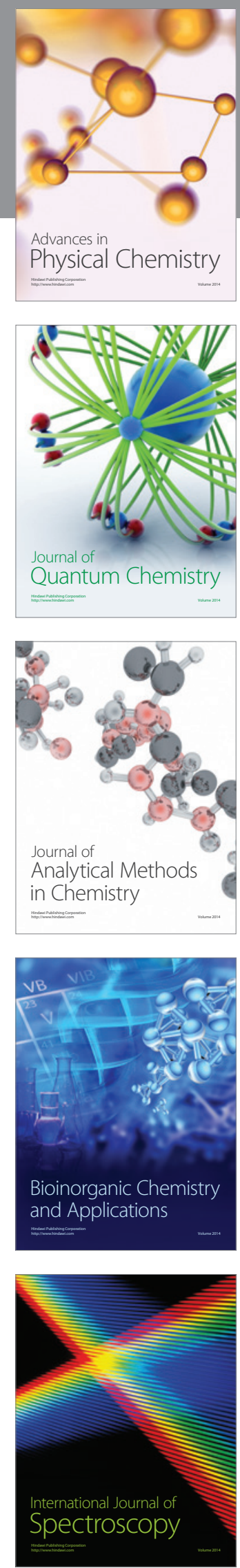